\title{
Preface: saving climate science
}

Climate science has long been in trouble and I wish to help it with this book. As the climate scientist Michael E. Mann (2012) vividly recounts in his autobiography, the 'climate wars' and heated public disputes about the accuracy of climate science originated in the early 1990s when the United Nations Intergovernmental Panel on Climate Change (IPCC) published its first report summarising the scientific evidence of climate change for policy-makers. As Mann also narrates in first person, the most malicious personal attack on climate science occurred in November 2009, when thousands of private emails and documents sent and received by prominent climate scientists (including Mann himself) were stolen and published online. The anonymous hackers justified this ominous attack by saying, 'We feel the climate science is, in the current situation, too important to be kept under wraps. We hereby release a random selection of correspondence, codes and documents. Hopefully, it will give some insights into the science and the people behind it' (Pearce, 2010: 166). The hackers indeed succeeded in opening the workings of climate science to the public. For months, the climate scientists whose emails had been stolen were the focus of media attention and were investigated by multiple university and parliamentary inquiries under allegations of obstruction to open access to scientific data and failures of objectivity in peer-review and research assessment. The hacking and its aftermath, as the House of Commons admitted in its inquiry report, were a 'traumatic and challenging experience for all involved and to the wider world of science' (House of Commons Science and Technology Committee, 2010: 33).

The authority of climate scientists has been eroded since the turn of the twentyfirst century by what seems to be a more general phenomenon: what happens inside many sciences has become visible to a highly educated and self-confident citizenry, as television and the Internet have opened up once exclusive and hidden spaces to public scrutiny (Collins, 2014; Gregory and Miller, 1998). The challenge faced by climate scientists is depicted in a cartoon published in The Economist shortly after the hacking (Figure P.1): the robust stock of knowledge that has been privately generated and validated by thousands of climate scientists for years (represented by a fortified tower of IPCC reports in the cartoon) is now under direct assault and surveillance from outside experts (as seen by the fact that these outsiders wear laboratory coats in the cartoon). 


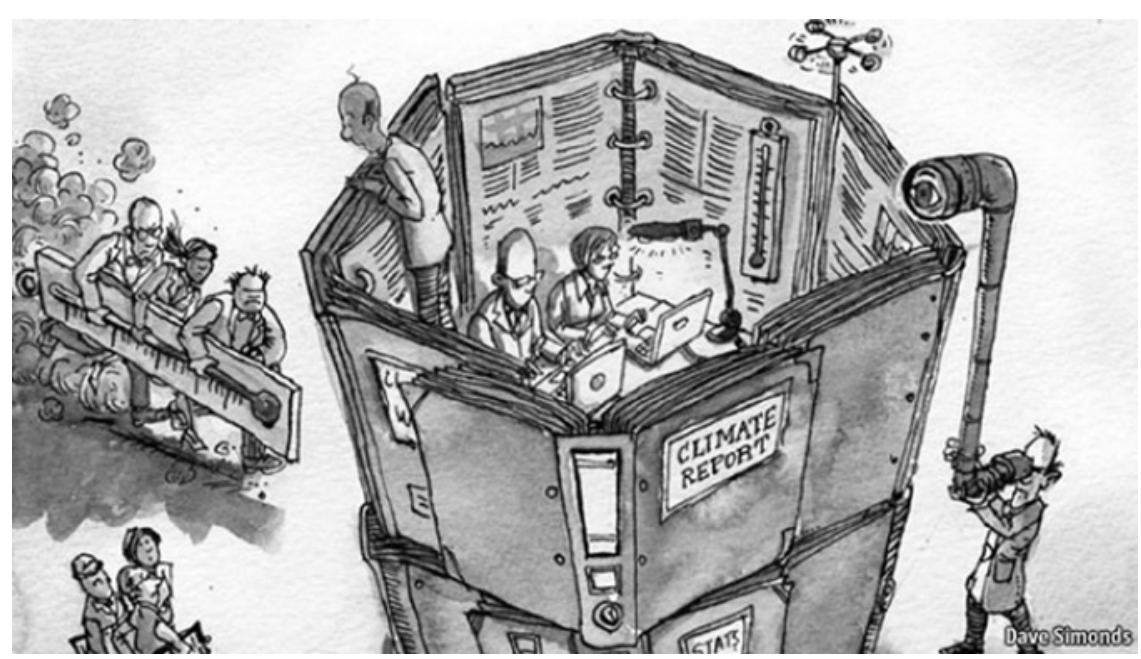

P. 1 Climate scientists and their work have been under intense public scrutiny.

I am of the opinion that there is little that climate scientists, individually or collectively, can do to reverse a broader secular trend affecting the credibility of technical and scientific experts and traditional authorities (Barnes, 2005). The growing 'culture of suspicion' towards climate scientists has to do with: i) broader social changes caused by the expansion of formal education and the increasing accessibility of information, which have given rise to the so-called 'climate sceptical blogosphere' (Sharman, 2014); and ii) the actual changes that have occurred within climate science throughout the twentieth century, the professionalisation of climate science and its increased associations with political institutions, which have meant that climate scientists are not perceived as independent experts (Lahsen, 2013a; Agar, 2012: 397; Edwards, 2010). Consequently, these 'uninvited guests', who continuously show up on the doorsteps of the fortified house of climate science and who cause some inconvenience to its inhabitants, are not likely to disappear in the future. Strategically, I suggest, climate scientists should acclimatise to this new context by making themselves and their work accountable to their sceptical audiences and demonstrating why they are virtuous and competent and why climate science is worthy of public trust and money (O’Neill, 2013, 2002; Jasanoff, 2010; Hulme and Ravetz, 2009; Shapin, 1994).

I have written this book because I worry that climate scientists might not be well equipped to survive future public examinations of their work, not because climate science is not robust enough but because the source of its robustness - the fact that climate science is made by humans - is publicly condemned and dismissed by scientists themselves. I came to this conclusion after analysing the way individual scientists and scientific institutions publicly responded to the allegations made against them after the hacking episode in November 2009 (Ramírez-i-Ollé, 2015a). To my surprise, I discovered that scientists agreed with their critics that the stolen 
emails were embarrassing. Rather than providing more context for the electronic correspondence - by explaining that scientific facts are a product of human labour and negotiation and that disciplinary commitments, politics and personal relationships have a bearing on scientists' handling, interpretation and reporting of data - some scientists criticised the very social processes and influences that constitute the practical reliability of all sciences. As one physics professor put it, 'Science often falls short of its ideals, and the climate debate has exposed some shortcomings. Science is done by people, who need grants, who have professional rivalries, limited time, and passionately held beliefs. All these things can prevent us from finding out what works' (Butterworth, 2010: emphasis added). By upholding a conventional and very false image of the procedures of science, scientists might have inadvertently given weaponry to the critics of climate science who - because of bad faith or genuine ignorance - uphold scientific standards that no science will ever reach. If climate scientists continue romanticising their work (or allow others to do so), they will likely generate further public distrust and cynicism. After all, we should not be surprised that educated and well-informed people look for alternative explanations and experts when things do not turn out to be quite as they were always told.

The story of how things have got to a point at which scientists have surrounded themselves by walls of hype, myth and denial is too long to be told here (see Sarewitz, 2016 and Shapin, 2001 for explanations); I instead aim to bring these walls down and make the now fairly open house of climate science more comprehensible to outsiders. Climate science needs neither heroes nor Public Relations agents to regain its credibility; rather, it needs sociologists, historians, anthropologists and philosophers of science (in short, Science and Technology Studies scholars) who can challenge damaging mythologies about climate science with what I call 'epistemographies of climate change', or empirically rich and contextualised accounts of climate knowledge in the making. This book draws on a long tradition of epistemographic studies in order to tell the story of how, with what confidence and on what grounds, a small group of climate scientists - 'dendroclimatologists' specifically - were able to generate knowledge of climate change in Scotland from the study of the Caledonian forests and to link their specific data to broader trends of global climate change. Ultimately, I hope that, by offering a detailed account of the social life of climate science, readers will grant authority to climate science not because it justifies itself as a self-sufficient worldview or substitute of God, but because, as shown in this book, it is a fine human achievement and our most reliable source of available expertise. 